\title{
The Determination of Twin Zygosity by Means of a Mailed Questionnaire
}

\author{
Svenn Torgersen
}

The Norwegian Research Council for Science and the Humanities, Center for Research in Clinical Psychology, University of Oslo

\begin{abstract}
A mailed questionnaire dealing with similarity in childhood, and how often and by whom the twins were mixed up, was applied to 290 same-sex adult twin pairs. For about $75 \%$ of pairs ten genetic markers were analysed. The agreement in zygosity classification between questionnaire and blood typing was high. Irrespective of whether raw scores or discriminant function analysis was applied, the agreement was nearly $95 \%$. When a decision tree was applied, the percentage rose to nearly $96 \%$. Considering that probably four of the twin pairs were wrongly classified as MZ by genetic markers, the percentage rose to 96 and 98 , respectively.
\end{abstract}

Key words: Twin zygosity, Determination, Questionnaire studies, Norwegian population

\section{INTRODUCTION}

The determination of zygosity in early twin research was, as a rule, based solely upon the researcher's intuitive impression of similarity in appearance and anthropometric characteristics. Especially through the influential papers of Smith and Penrose [11] and Sutton et al [12], blood typing has then increasingly been used for the last two decades. Even so, however, there always remains a probability that a pair of twins concordant with respect to all blood groups and antigens and hence classified as monozygotic (MZ) in reality is dizygotic (DZ). A much more accurate zygosity determination could be obtained through tissue transplantation, but this method is expensive and too complicated for routine use. In recent years, the determination of zygosity by means of similarity and dissimilarity in appearance has again gained popularity. As compared to earlier studies, however, the method is now much more refined.

Cederlöf et al [2] used a questionnaire asking if the twins were "as like as two peas in a pod" or "of a family likeness only." They found that $99 \%$ of the pairs where both twins had answered that they were "as like as two peas" could be classified as MZ by means of genetic markets, and $92 \%$ of the pairs where both twins had answered "only family likeness" were classified as DZ by means of genetic markers. 
Nichols and Bilbro [8] asked the twins if they were mixed up by parents, teachers, and friends. They also asked about similarity of eye and hair colour, height, and weight, and combined these characteristics. By establishing decision rules they obtained a $93 \%$ agreement between similarity determination and genetic marker determination.

In building up the Danish Twin Register, Hauge et al [5] also tried to determine zygosity by means of a mailed questionnaire. Pairs in which the partners claimed that they were similar in appearance and were mixed up by parents, friends, and acquaintances were classified as MZ. Pairs that were not similar in appearance and not mixed up were classified as DZ. About $5 \%$ of the same-sex twins were unclassified as their answers about similarity in appearance and mixing-up were contradictory.

Cohen et al [3] mailed a questionnaire to parents of twins asking whether the twins looked as like as two peas in a pod and if they were mixed up by parents, other family members, or strangers. The replies were compared to the zygosity determined by genetic markers. The question "as like as two peas" was answered with "yes" by all the parents of MZ pairs, but regrettably also by almost half of the parents of $\mathrm{DZ}$ pairs. The question that best discriminated between $\mathrm{MZ}$ and $\mathrm{DZ}$ twins was whether it was difficult for strangers to tell them apart. Parents of the MZ twins answered "yes" in $84 \%$ of the cases compared to only $1 \%$ of the parents of the DZ twins. By adding height, weight, facial appearance, hair colour, eye colour, and complexion, and applying discriminant analysis and posterior application of the discriminant function, only three of $155(2 \%)$ were misclassified according to blood typing.

Sarna et al [10] also used questions asking whether the twins were "as like as two peas in a pod" or "of ordinary family likeness," and whether the twin partners were "so similar in appearance at school age that people had difficulty in telling you apart." They used two criteria to determine zygosity. The stricter one required that both twin partners give the same answer and that there be no contradictions between the answer to the question about similarity in appearance and mixing-up at school age. By this criterion $9 \%$ of the pairs were left in the nonclassified group because of disagreement or contradiction. The other criterion consisted of a complex procedure through which the remaining pairs would be classified. No disagreement was found between the use of the mailed questionnaire and the use of 11 polymorphic marker systems in the determination of zygosity.

Questions about similarity in appearance seem thus to be almost as good an indicator of zygosity as genetic markers. In addition they are less expensive and easier to carry out, especially in large-scale epidemiological research. The problem is, however, to establish zygosity in pairs where the twin partners give different answers and where there exist contradictions between the answers to different questions.

The aim of the present study is to try to confirm the validity of a short and simple mailed questionnaire, and to compare different statistical and practical decision rules in zygosity assessment.

\section{MATERIALS AND METHODS}

\section{Subjects}

The total sample consisted of 299 same-sexed twin pairs. At least one of the twin partners had been a psychiatric in-patient or treated as an out-patient in Norway for milder psychiatric disorders. The ascertainment procedure is described elsewhere [13]. In less than $9 \%$ of the twin pairs one or both of the twins refused to participate in the investigation. The zygosity of six of the twin pairs had been determined in an earlier twin study. Three pairs had been brought up apart and could therefore not fill out 
the questionnaire about similarity and mixing-up in childhood. The subjects in this study therefore consisted of 290 same-sexed twin pairs, 196 female and 94 male. The ages ranged from 18 to 67 years with a mean of 44 years.

\section{Questionnaire}

A translated version of the questionnaire is presented in Table 1. As can be seen, it is similar to those used by Cederlöf et al [2], Nichols and Bilbro [8], and Cohen et al [3] .

\section{Blood Typing}

Blood samples were obtained from both twins in $215(74.1 \%)$ of the twin pairs. Tests were performed by the Institute of Forensic Medicine, Rikshospitalet, Oslo, with respect to ABO, MNS, Rh (C, D, E. c, e), Kell, haptoglobin, group specific component, phosphoglucomu tase, C3 complement component, acid phosphatase, and glutamic-pyruvic transaminase. Not all tests could be performed for all twins. The determination of zygosity followed Smith and Penrose [11] and Hummel and Baumgarten [6]. The gene frequencies in the Norwegian population were taken from Berg [1]. For a pair classified as $\mathrm{MZ}$, the median probability of dizygosity was estimated as 0.0034 .

\section{RESULTS}

Table 2 shows that there is a highly significant relationship between the answers about similarity in childhood and the results of blood typing. If pairs where one or both twins reply "As like as two peas in a pod" are considered MZ, and the others DZ, 203 of 215 , or $94.5 \%$, are assigned the same zygosity with the questionnaire and the blood typing.

Table 3 shows that there also is a highly significant relationship between the answers about how often the twins were mixed up and zygosity according to blood typing. If the answer "Mixed up very often" from one or both of the twins is taken as evidence of monozygosity and the other pairs are considered DZ, $92.6 \%$ of the pairs are assigned the same zygosity with the questionnaire and the blood typing.

As shown in Table 4, the answers about who mixed up the twins are almost completely discriminating, especially when the answer "Mixed up by others" from both of the twins is not taken in to consideration. If the answer "Mixed up by others" from both of the twins, or the answer "Mixed up by nobody" from one or both of the twins is taken as evidence of dizygosity, $91.2 \%$ of the twins are assigned the same zygosity with the questionnaire and the blood typing.

\section{TABLE 1. The Questionnaire}

Below you will find some questions about how alike you and your twin were in childhood. Please mark off the answers which are most fitting.

1. Were you and your twin "as like as two peas in a pod"?

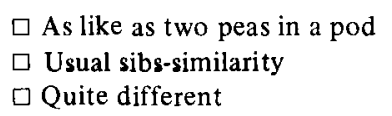

2. Were you and your twin mixed up as children?

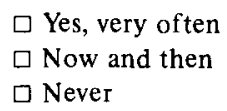

3. In that case, by whom were you mixed up?
$\square$ Parents
$\square$ Teachers
$\square$ Others
$\square$ Nobody 
TABLE 2. Relationship Between Answers to the Questions A bout Similarity in Childhood and Zygosity According to Blood Typing

\begin{tabular}{|c|c|c|c|c|c|c|}
\hline \multirow[b]{3}{*}{ Answers of the twins } & \multicolumn{6}{|c|}{$\begin{array}{l}\text { Zygosity according } \\
\text { to blood typing }\end{array}$} \\
\hline & \multicolumn{2}{|c|}{$M Z$} & \multicolumn{2}{|c|}{$\mathrm{DZ}$} & \multicolumn{2}{|c|}{ Total } \\
\hline & $\mathrm{N}$ & $\%$ & $N$ & $\%$ & $\mathrm{~N}$ & $\%$ \\
\hline $\begin{array}{l}\text { Both answer: "As like as } \\
\text { two peas." }\end{array}$ & 81 & 37.7 & 1 & 0.5 & 82 & 38.1 \\
\hline $\begin{array}{l}\text { One answers: "As like as } \\
\text { two peas," the other gives } \\
\text { a different answer. }\end{array}$ & 8 & 3.7 & 2 & 0.9 & 10 & 4.7 \\
\hline $\begin{array}{l}\text { Both answer: "Usual sibs- } \\
\text { similarity." }\end{array}$ & 6 & 2.8 & 61 & 28.4 & 67 & 31.2 \\
\hline $\begin{array}{l}\text { One answers: "Usual sibs- } \\
\text { similarity," the other an- } \\
\text { swers: "Quite different." }\end{array}$ & 2 & 0.9 & 21 & 9.8 & 23 & 10.7 \\
\hline $\begin{array}{l}\text { Both answer: "Quite } \\
\text { different." }\end{array}$ & 1 & 0.5 & 32 & 14.9 & 33 & 15.3 \\
\hline Total & & & & & 215 & 100.0 \\
\hline
\end{tabular}

$\chi^{2}=171.8, P<0.001$

TABLE 3. Relationship Between Answers to the Questions A bout Mixing up in Childhood and Zygosity According to Blood Typing

\begin{tabular}{|c|c|c|c|c|c|c|}
\hline \multirow[b]{3}{*}{ Answers of the twins } & \multicolumn{6}{|c|}{ Zygosity according to blood typing } \\
\hline & \multicolumn{2}{|c|}{$\mathrm{MZ}$} & \multicolumn{2}{|c|}{$\mathrm{DZ}$} & \multicolumn{2}{|c|}{ Total } \\
\hline & $\mathrm{N}$ & $\%$ & $\mathrm{~N}$ & $\%$ & $\mathrm{~N}$ & $\%$ \\
\hline $\begin{array}{l}\text { Both answer: "Mixed up very } \\
\text { often." }\end{array}$ & 70 & 32.6 & 2 & 0.9 & 72 & 33.5 \\
\hline $\begin{array}{l}\text { One answers: "Mixed up very } \\
\text { often," the other gives a } \\
\text { different answer. }\end{array}$ & 16 & 7.4 & 2 & 0.9 & 18 & 8.3 \\
\hline $\begin{array}{l}\text { Both answer: "Mixed up now } \\
\text { and then." }\end{array}$ & 6 & 2.8 & 21 & 9.8 & 27 & 12.6 \\
\hline $\begin{array}{l}\text { One answers: "Mixed up now } \\
\text { and then," the other answers: } \\
\text { "Never mixed up." }\end{array}$ & 2 & 0.9 & 17 & 7.9 & 19 & 8.8 \\
\hline Both answer: "Never mixed up." & 4 & 1.9 & 75 & 34.9 & 79 & 36.8 \\
\hline Total & & & & & 215 & 100.0 \\
\hline
\end{tabular}

$\chi^{2}=160.4, \mathrm{P}<0.001$

The answers "As like as two peas in a pod," "Mixed up very often," and "Mixed up by parents" were given the score 1; "Usual sib-similarity," "Mixed up now and then," and "Mixed up by teachers," the score 2; "Quite different," "Never mixed up," and "Mixed up by others," the score 3; and "Mixed up by nobody" the score 4 . The scores 
for both twins were summarized and Table 5 gives the result. It was found that if the score was 12 or less, almost all pairs were $\mathrm{MZ}$ according to blood typing; if the score was 14 or higher, almost all pairs were $\mathrm{DZ}$; if the score was 13 , three were $\mathrm{MZ}$ and three

TABLE 4. Relationship Between Answers About Who Mixed up the Twins and Zygosity According to Blood Typing

\begin{tabular}{|c|c|c|c|c|c|c|}
\hline \multirow[b]{3}{*}{ Answers of the twins } & \multicolumn{6}{|c|}{ Zygosity according to blood typing } \\
\hline & \multicolumn{2}{|l|}{$\mathrm{MZ}$} & \multicolumn{2}{|l|}{$\mathrm{DZ}$} & \multicolumn{2}{|l|}{ Total } \\
\hline & $\mathrm{N}$ & $\%$ & $\mathrm{~N}$ & $\%$ & $\mathrm{~N}$ & $\%$ \\
\hline $\begin{array}{l}\text { Both answer: "Mixed up by } \\
\text { parents." }\end{array}$ & 28 & 13.0 & 0 & & 28 & 13.0 \\
\hline $\begin{array}{l}\text { One answrs: "Mixed up by } \\
\text { parents," the other gives } \\
\text { another answer. }\end{array}$ & 26 & 12.1 & 0 & & 26 & 12.1 \\
\hline $\begin{array}{l}\text { Both answer: "Mixed up by } \\
\text { teachers." }\end{array}$ & 18 & 8.4 & 1 & 0.5 & 19 & 8.8 \\
\hline $\begin{array}{l}\text { One answers: "Mixed up by } \\
\text { teachers," the other answers: } \\
\text { "Mixed up by others." }\end{array}$ & 9 & 4.2 & 1 & 0.5 & 10 & 4.7 \\
\hline $\begin{array}{l}\text { Both answer: "Mixed up by } \\
\text { others." }\end{array}$ & 13 & 6.0 & 27 & 12.6 & 40 & 18.6 \\
\hline $\begin{array}{l}\text { One answers: "Mixed up by } \\
\text { others," the other answers: } \\
\text { "Mixed up by nobody." }\end{array}$ & 0 & & 13 & 6.0 & 13 & 6.0 \\
\hline $\begin{array}{l}\text { Both answer: "Mixed up by } \\
\text { nobody." }\end{array}$ & 4 & 1.9 & 75 & 34.9 & 79 & 35.8 \\
\hline Total & & & & & 215 & 100.0 \\
\hline
\end{tabular}

$x^{2}=151.9, P<0.001$.

TABLE 5. Relationship Between Questionnaire Scores and Zygosity According to Blood Typing

\begin{tabular}{lrrr}
\hline & \multicolumn{3}{c}{ Zygosity according to blood typing } \\
\cline { 2 - 4 } Score & MZ & DZ & Total \\
\hline 6 & 26 & 0 & 26 \\
7 & 15 & 0 & 15 \\
8 & 22 & 0 & 22 \\
9 & 7 & 0 & 7 \\
10 & 10 & 1 & 11 \\
11 & 6 & 1 & 7 \\
12 & 4 & 1 & 5 \\
13 & 3 & 3 & 6 \\
14 & 1 & 15 & 16 \\
15 & 0 & 8 & 8 \\
16 & 0 & 8 & 8 \\
17 & 0 & 3 & 3 \\
18 & 1 & 29 & 30 \\
19 & 2 & 18 & 20 \\
20 & 1 & 30 & 31 \\
Total & 98 & 117 & 215 \\
\hline
\end{tabular}


were $\mathrm{DZ}$. If the cutting point between $\mathrm{MZ}$ and $\mathrm{DZ}$ is set between 12 and 13 or 13 and 14,204 out of 215 , or $94.9 \%$, are assigned the same zygosity with the questionnaire and the blood typing.

Figure 1 shows the distribution of scores. We find that it is bimodal (perhaps trimodal) with the $\mathrm{MZ}$ pairs in the one end and the DZ pairs in the other. There is very little overlapping.

The scores were subjected to a discriminant analysis using the University of Pittsburgh's Statistical Package for the Social Sciences - 10 [9]. The direct and stepwise selection gave the same discrimination, and the results with the direct method are presented in

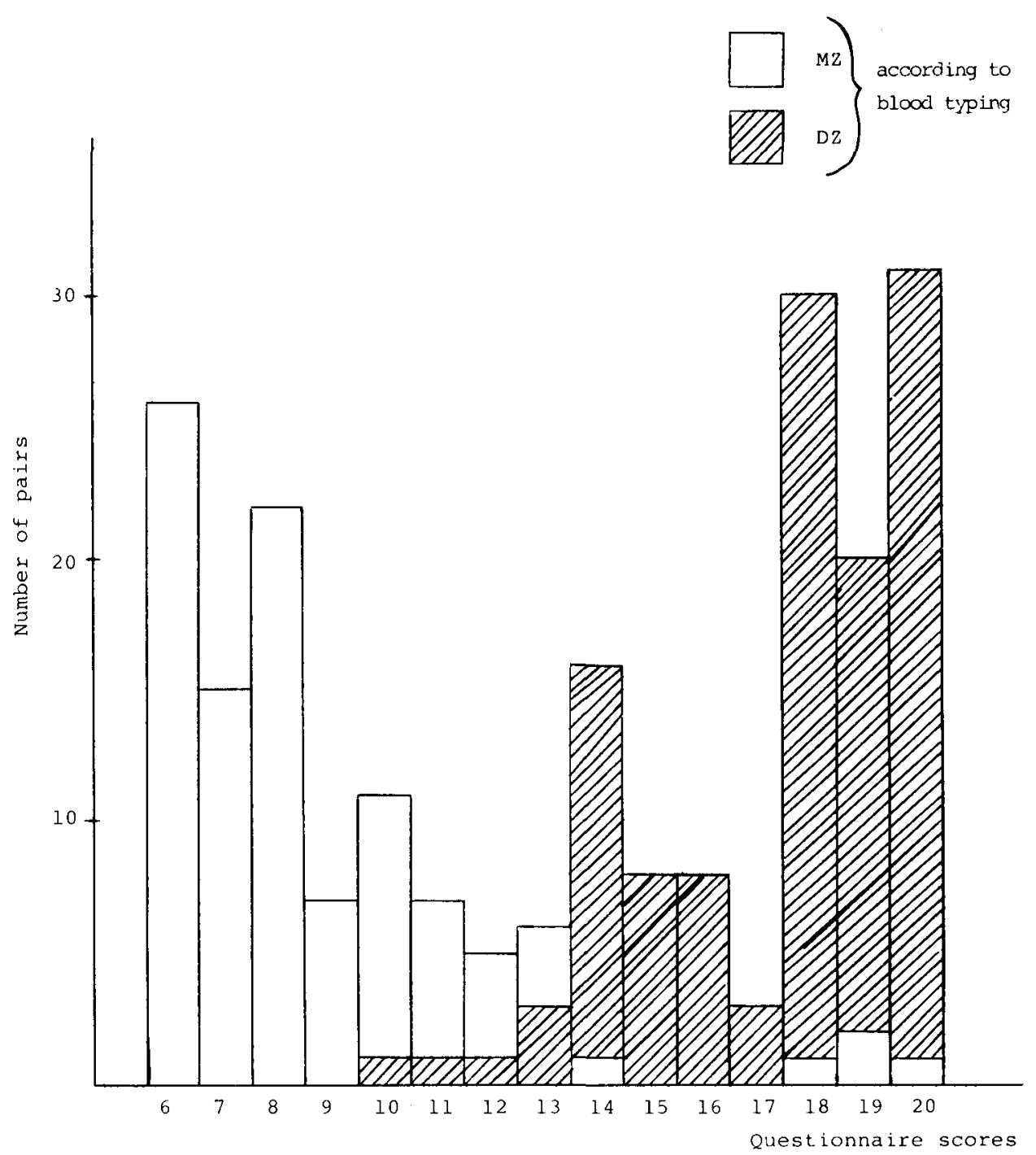

Fig. 1. The distribution of questionnaire scores for $M Z$ and $D Z$ twin pairs according to blood typing. 
Table 6, which shows the mean and the standard discriminant function coefficients for the three sets of questions. The coefficients were similar for all three sets of questions. The discrimination was highly significant. Table 7 shows the discriminant scores and Figure 2 the distribution of scores. The distribution is similar to that of unadjusted raw scores (Fig. 1), with very little overlapping between $\mathrm{MZ}$ and $\mathrm{DZ}$ twins according to blood typing.

Table 8 shows how many twins were assigned the same zygosity by posterior application of the discriminant function to the questionnaire scores and by blood typing. Of 98 twins classified as MZ by blood typing, $92(93.9 \%)$ were also classified as MZ by the discriminant function, and 112 out of 117 , or $95.7 \%$, were classified as DZ both by blood typing and the discriminant function. Of 215 pairs 204 , or $94.9 \%$, were assigned the same zygosity by blood typing and the discriminant function based upon the questionnaire scores.

TABLE 6. Mean and Standardized Discriminant Function Coefficients for the Three Questions in the Questionnaire

\begin{tabular}{|c|c|c|c|}
\hline \multirow[b]{2}{*}{ Questions } & \multicolumn{2}{|c|}{ Means } & \multirow{2}{*}{$\begin{array}{l}\text { Standardized } \\
\text { discriminant } \\
\text { function } \\
\text { coefficients }\end{array}$} \\
\hline & $\mathrm{MZ}$ & $\mathrm{DZ}$ & \\
\hline Similarity & 2.31 & 4.69 & -0.39880 \\
\hline How of ten mixed up & 2.50 & 5.33 & -0.30608 \\
\hline Who mixed up the twins & 3.79 & 7.37 & -0.34161 \\
\hline
\end{tabular}

$\mathrm{X}^{2}=277.2, \mathrm{P}<0.001$

TABLE 7. Relationship Between the Discriminant Scores of the Questionnaire and Zygosity According to Blood Typing

\begin{tabular}{lrrr}
\hline & \multicolumn{3}{l}{$\begin{array}{l}\text { Zygosity according to } \\
\text { blood typing }\end{array}$} \\
\cline { 2 - 4 } Discriminant scores & MZ & DZ & Total \\
\hline $1.300-1.399$ & 26 & 0 & 26 \\
$1.100-1.299$ & 15 & 0 & 15 \\
$0.900-1.099$ & 27 & 0 & 27 \\
$0.700-0.899$ & 9 & 1 & 10 \\
$0.500-0.699$ & 6 & 0 & 6 \\
$0.300-0.499$ & 5 & 1 & 6 \\
$0.100-0.299$ & 4 & 3 & 7 \\
$-0.100-0.099$ & 2 & 1 & 3 \\
$-0.300--0.101$ & 0 & 21 & 21 \\
$-0.500--0.301$ & 0 & 12 & 12 \\
$-0.700--0.501$ & 0 & 0 & 0 \\
$-0.900--0.701$ & 1 & 29 & 30 \\
$-1.100--0.901$ & 2 & 19 & 21 \\
$-1.300--1.101$ & 0 & 0 & 0 \\
$-1.399--1.301$ & 1 & 30 & 31 \\
Total & 98 & 117 & 215 \\
\hline
\end{tabular}


TABLE 8. Relationship Between Classification According to Blood Typing and Application of the Discriminant Function to the Questionnaire Scores

\begin{tabular}{|c|c|c|c|c|c|c|}
\hline \multirow[b]{3}{*}{$\begin{array}{l}\text { Zygosity according to } \\
\text { blood typing }\end{array}$} & \multicolumn{6}{|c|}{ Zygosity according to questionnaire } \\
\hline & \multicolumn{2}{|l|}{$\underline{\mathrm{MZ}}$} & \multicolumn{2}{|l|}{$\underline{\mathrm{DZ}}$} & \multicolumn{2}{|c|}{ Total } \\
\hline & $\mathrm{N}$ & $\%$ & $\mathrm{~N}$ & $\%$ & $\mathbf{N}$ & $\%$ \\
\hline $\mathrm{MZ}$ & 92 & 93.9 & 6 & 6.1 & 98 & 100.0 \\
\hline $\mathrm{DZ}$ & 5 & 4.3 & 112 & 95.7 & 117 & 100.0 \\
\hline \multicolumn{7}{|c|}{ Correctly classified: $94.9 \%$} \\
\hline
\end{tabular}

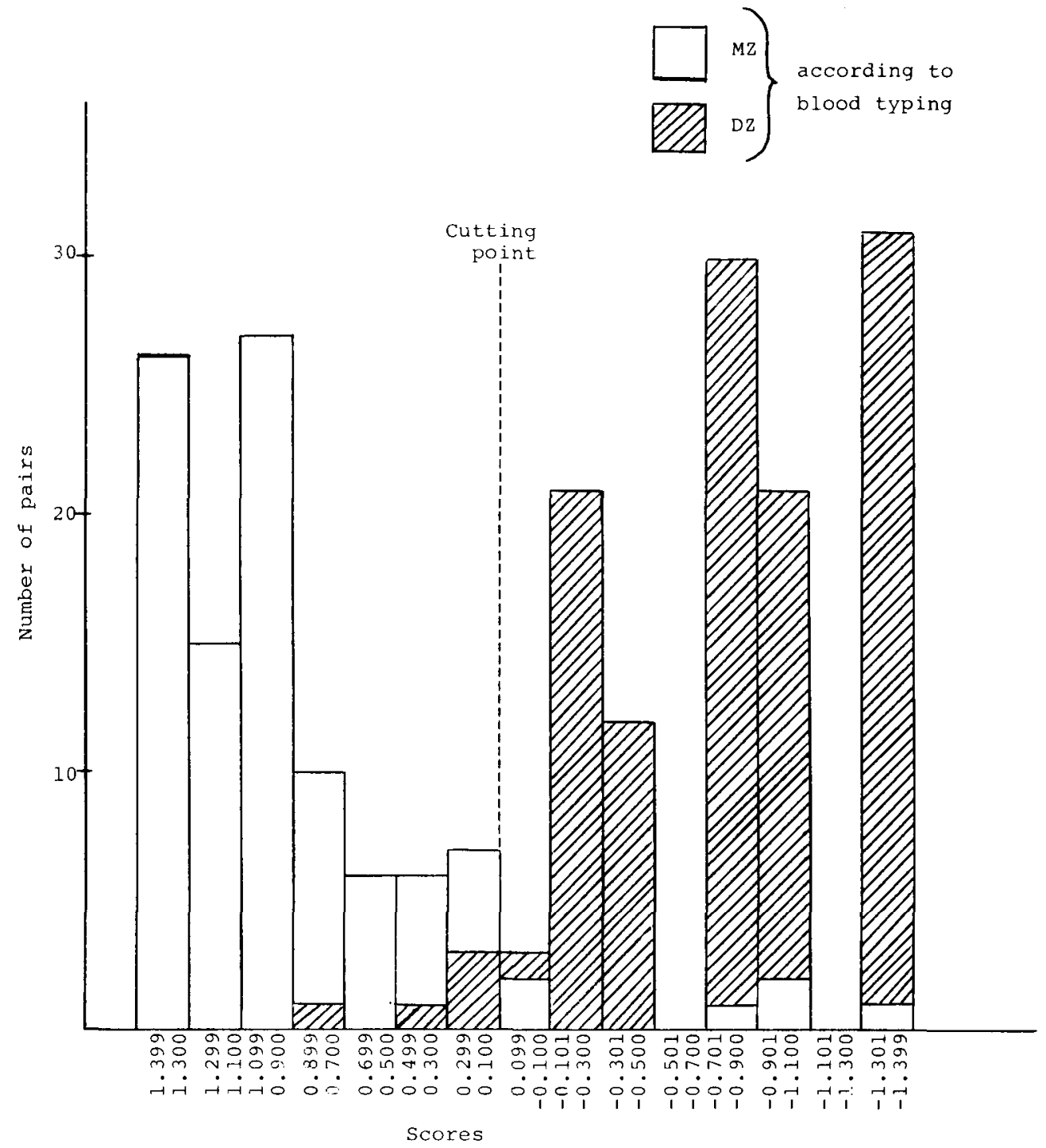

Fig. 2. The distribution of discriminant scores for $M Z$ and $D Z$ twin pairs according to blood typing. 
Figure 3 presents a decision tree as an alternative way to classify the twins according to their answers to the questionnaire. The answers concerning mixing up are first taken into consideration. If one of the twins answers that they were mixed up by parents or teachers, and the other that they were mixed up by parents, teachers, or others, the twins are classified as MZ. If one or both answer that they were not mixed up by anybody, the twins are classified as DZ. If both answer that they were mixed up by others, the answers concerning similarity are examined. If both twins answer that they are as like as two peas, they are classified as MZ. If other answers are given, the answers concerning mixing up are examined. If one or both twins reply that they were mixed up very often, the twins are classified as MZ. If both answer that they were mixed up now and then, they are classified as DZ. By these rules, 206 out of 215 , or $95.8 \%$, were classified in the same category by the blood typing and the questionnaire.

The discriminant function was applied to the 78 twin pairs where the blood typing was lacking: 22 were classified as $\mathrm{MZ}$ and 56 as DZ. Four of the twin pairs that were classified as $\mathrm{MZ}$ by the blood typing were different in hair colour, height, and face morphology. One of them had a total questionnaire score of 18 , one of 19 , and one of 20 . One had a discriminant function score of -1.345 , two of -1.081 , and one of -0.0809 . In Figures 1 and 2 they are located in the right-hand side of the distribution.

According to Essen-M $\phi$ ller [4] these anthropometric characteristics are more conclusive than blood typing. Consequently, I believe that these four pairs in reality are DZ, notwithstanding identical blood typing, and they are hence classified as DZ in all subsequent analyses.

Table 9 shows the number of $\mathrm{MZ}$ and $\mathrm{DZ}$ pairs if genetic markers are used as a criterion for zygosity diagnosis when blood tests are available (except for the four pairs mentioned above) and the discriminant function for the rest. In addition, the table presents the zygosity of the twins who were brought up apart and hence have not been able to fill out the questionnaire about similarity in childhood, and the zygosity of pairs for whom zygosity had been determined in an earlier study by means of blood typing. Of the 299 pairs, $124(41.5 \%)$ turned out to be $\mathrm{MZ}$ and $175(58.5 \%) \mathrm{DZ}$.

\section{DISCUSSION}

Similarly to earlier studies $[2,3,5,8,10]$, this study has demonstrated a remarkable agreement between the twins' answers to a questionnaire about similarity in appearance and the analysis of genetic markers. If the twins are asked to answer the single question: "When growing up, were you as like as two peas in a pod, of unusual sib-similarity, or quite different?," only 12 out of 215 pairs are misclassified with regard to zygosity, if the results of blood typing are taken as the final answer. If they are also asked about how often they were mixed up and by whom, and the answers are combined, only one more pair is correctly classified.

The study also demonstrated that discriminant function analysis did not yield additional information. No other pairs are correctly classified. The better way of diagnosing twin pairs with regard to zygosity is by a decision tree. In this way only nine pairs were misclassified, if genetic markers are regarded as the "truth."

It is, however, not warranted to accept blood typing as absolute evidence for the twins' zygosity. The median probability for a twin pair to be $\mathrm{DZ}$ even if all the blood systems were identical was in this study 0.034 ; in other words, $3.4 \%$ of the pairs classified as $\mathrm{MZ}$ should be expected to be $\mathrm{DZ}$. As mentioned, four out of 98 , or $4.1 \%$, of the pairs 
Mixed up by whom in childhood

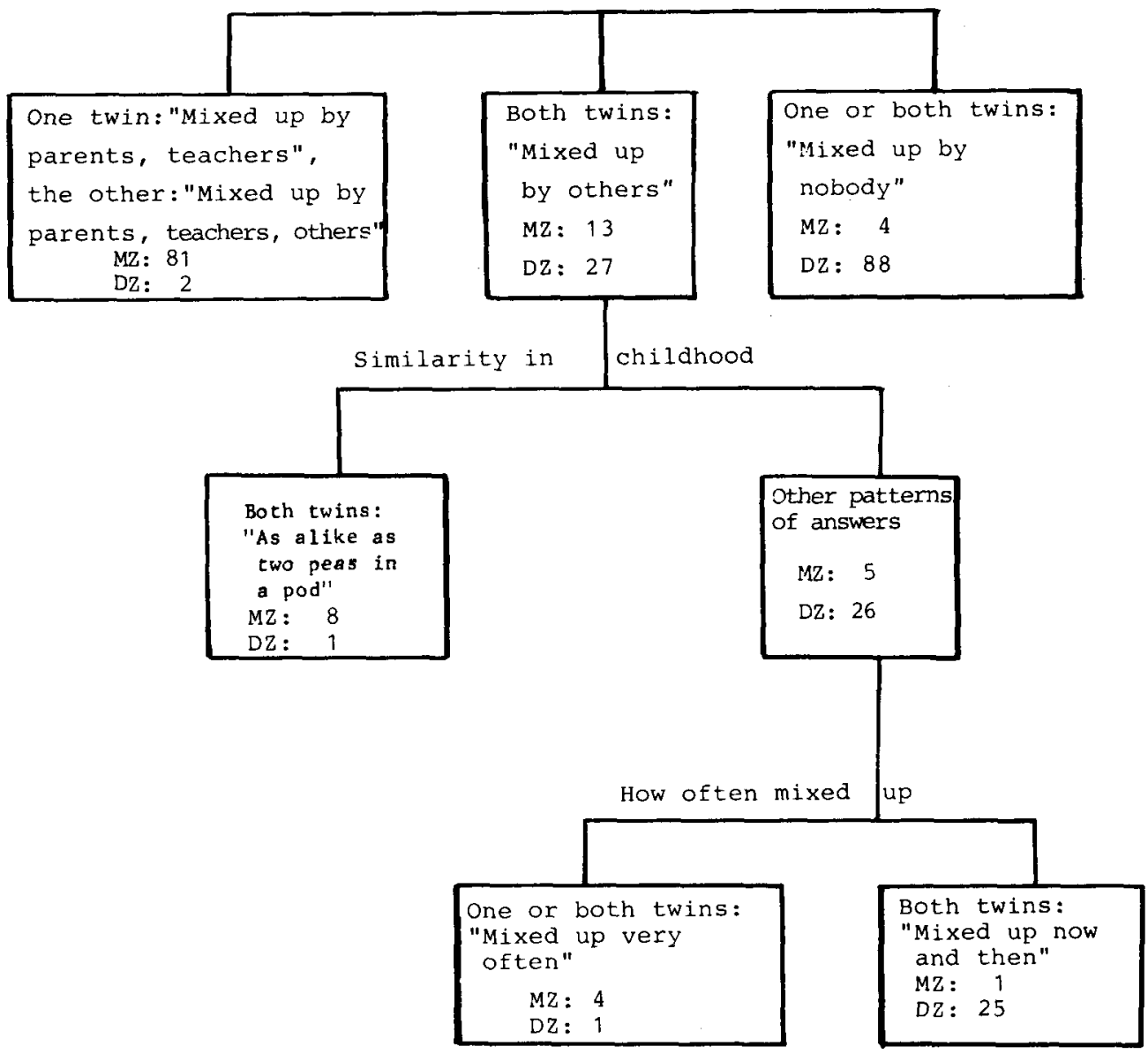

Fig. 3. The application of a decision tree in the classification of the twins according to the answers to the questions in the questionnaire, related to classification according to blood typing.

classified as $\mathrm{MZ}$ according to blood typing were very different in appearance. This number is fairly similar to the expected number of DZ pairs mistakenly classified as $M Z$ by means of blood typing. If these four pairs are considered as $\mathrm{DZ}$, the questionnaire correctly established the zygosity of 208 of 215 , or $96.7 \%$, of the twin pairs irrespective of whether the answers are summed or discriminant analysis is used. The decision tree correctly classified 211 out of 215 or $98.1 \%$ of the twin pairs with regard to zygosity.

Adding those pairs where blood samples were not obtained and which were hence classified according to discriminant function analysis of the questionnaire scores, the twin pairs brought up apart and the twin pairs where the zygosity had been determined in an earlier twin study, $41.5 \%$ of the twin pairs were classified as $\mathrm{MZ}$ and $58.5 \%$ as DZ. This is almost exactly the $41.7 \% \mathrm{MZ}$ expected from Weinberg's formula for the schizophrenic same-sexed twin population in Norway [7]. As schizophrenia is not over-or under-represented in the twin population, this might also be the distribution of zygosity in the total population in Norway. The questionnaire used in assessing zygosity should 


\begin{tabular}{|c|c|c|c|}
\hline \multirow[b]{2}{*}{ Sources of zygosity determination } & \multicolumn{2}{|c|}{ Final classification } & \multirow[b]{2}{*}{ Total } \\
\hline & MZ & $\mathrm{DZ}$ & \\
\hline $\begin{array}{l}\text { Agreement between blood typing and } \\
\text { questionnaire discriminant function }\end{array}$ & 92 & 112 & 204 \\
\hline $\begin{array}{l}\text { No agreement, classified according to } \\
\text { blood typing }\end{array}$ & 5 & 2 & 7 \\
\hline $\begin{array}{l}\text { No agreement, classified according to } \\
\text { questionnaire and appearance }\end{array}$ & & 4 & 4 \\
\hline $\begin{array}{l}\text { No blood sample available, classified according } \\
\text { to questionnaire discriminant function }\end{array}$ & 21 & 54 & 75 \\
\hline $\begin{array}{l}\text { Brought up apart, hence no questionnaire, } \\
\text { but blood typing }\end{array}$ & 2 & 1 & 3 \\
\hline $\begin{array}{l}\text { Zygosity determined in an earlier twin study } \\
\text { by means of blood typing }\end{array}$ & 4 & 2 & 6 \\
\hline Total twin sample & $124(41.5 \%)$ & $175(58.5 \%)$ & $299(100.0 \%)$ \\
\hline
\end{tabular}

therefore yield a fairly correct and valid diagnosis. It is, however, important to note that the value of such a questionnaire depends upon the genetic homogeneity of the population. If both twins differ in a similar way with respect to the usual traits of the population, they may be considered as very similar even if in reality they are DZ. Norway consists of a homogeneous population, so that it is not very likely that the agreement between blood typing and questionnaire in this study should be greater than in studies in other countries.

\section{CONCLUSION}

In large-scale twin research there may be a considerable saving of time and money if zygosity is established by means of a mailed questionnaire. This study demonstrates that the chance of misclassifying the twin pairs is not much greater when one uses a mailed questionnaire than when an analy sis of a reasonable number of genetic markers is applied. And it is not necessary to use complex statistical procedures; a combination of the questionnaire raw scores is sufficient. It is desirable, by means of different studies, to establish rules of decision and use a decision tree. If it is important to have a very high probability for correct zygosity determination, this study shows that it is sufficient to get a blood sample from the twin pairs with an intermediate questionnaire score (between 10 and 14, Fig. 2). But, for all practical purposes, a misclassification close to $2 \%$ will only negligibly change the concordance rates in traditional twin studies.

\footnotetext{
Acknowledgments. This study was supported by grants from The Norwegian Research Council for Science and the Humanities.

The twins born before 1946 were obtained through the National Twin Register, Institute of Behavioral Sciences in Medicine, University of Oslo. Professor Einar Kringlen has given me valuable help and advice, for which I am very grateful. The twins born later were taken from the Norwegian Register for Inherited Disorders, Institute of Medical Genetics, University of Oslo. I gratefully acknowledge the assistance provided by the staff of the Institute of Medical Genetics, especially to Dr. Arvid Heiberg for his help and advice. I am also grateful to Dr. Halldis Lie, Institute of Forensic Medicine, Rikshospitalet, Oslo, who performed the blood and serum typing, and Dr. Paal Abrahamsen who read the manuscript.
} 


\section{REFERENCES}

1. Berg K (1973): Studies of polymorphic traits for the characterization of populations. The population of Scandinavia. Israel J Med Sci 9:1147-1155.

2. Cederlöf R, Friberg L, Jonsson E, Kaij L (1961): Studies on similarity diagnosis in twins with the aid of mailed questionnaires. Acta Genet (Basel) 11:338-362.

3. Cohen DJ, Dibble E, Grawe JM (1973): Separating identical from fraternal twins. Arch Gen Psychiatry 29:465-469.

4. Essen-M $\phi$ ller E (1941): Empirische Ähnlichkeitsdiagnose bei Zwillingen. Hereditas 27:1-50.

5. Hauge M, Harwald B, Fisher M, Gotlieb-Jensen K, Juel-Nielsen N, Raebild J, Shapiro R, Videbech $T$ (1968): The Danish twin register. Acta Genet Med Gemellol 17:315-331.

6. Hummel K, Baumgarten R (1970): Plausibilitaet der Monozygotic bei gleischgeschlechtlichen Zwillingen auf Grunde blutgruppen-serologischer Befunde. Humangentik 9:286-293.

7. Kringlen E (1967): Heredity and Environment in the Functional Psychoses. Oslo: Universitetsforlaget.

8. Nichols RC, Bilbro WC Jr (1966): The diagnosis of twin zygosity. Acta Genet 16:265-275.

9. Nie NH, Hull CH, Jenkins JG, Steinbrenner K, Bent DH (1975): "Statistical Package for the Social Sciences." New York: McGraw-Hill, Inc.

10. Sarna S, Kaprio J, Sistonen P, Ko senvuo M (1978): Diagnosis of twin zygosity by mailed questionnaire. Hum Hered 28:241-254.

11. Smith SM, Penrose LS (1955): Monozygotic and dizygotic twin diagnosis. Ann Hum Genet 19: $273-289$.

12. Sutton HE, Clark PJ, Schull WJ (1955): The use of multiallele genetic characters in the diagnosis of twin zygosity. J Hum Genet 7:180-188.

13. Torgerson $S$ (1980): Genetics of neurosis (in preparation).

Correspondence: Dr. Sven Torgersen, Center for Research in Clinical Psychology, PO Box 1039, Blindern, Oslo 3, Norway. 